\title{
Breast-Milk Amylase Activity in English and Gambian Mothers: Effects of Prolonged Lactation, Maternal Parity, and Individual Variations
}

\author{
ODILE DEWIT, BAKARY DIBBA, AND ANN PRENTICE \\ Medical Research Council Dunn Nutrition Unit, Cambridge, England [O.D., A.P.], and \\ Keneba, The Gambia [B.D.]
}

\begin{abstract}
Breast milk contains an amylase that may contribute to carbohydrate digestion in infants. The aim of our study was to determine whether mothers differ in their breast-milk amylase activity and whether the activity is maintained during prolonged lactation. This was investigated by measuring breast-milk amylase activity by hydrolysis of maltotetraose in 63 English mothers of parity 1-5 and 107 Gambian mothers of parity 1-12 who were at various stages of lactation (0.5-27 mo). Amylase was present in all samples and showed a great range of activity from 0.08 to $3.53 \mathrm{IU} / \mathrm{mL}$. Amylase activities did not vary during a feed nor over $24 \mathrm{~h}$, and each mother had a characteristic level of activity in her milk. Amylase activity was higher in the 1st trimester of lactation, and decreased by $35 \%(p<0.001)$ to a plateau at 6-27 mo. Gambian mothers of very high parity (parity 11-12) had 54\% of the activity of primiparous mothers $(p<0.001)$, after adjustment for stage of lactation. Using community data on milk volume, the estimated breast-milk amylase intake by breast-fed children was on the order of 800-1000 IU/24 h in the 1st trimester and $400 \mathrm{IU} / 24 \mathrm{~h}$ in the $2 \mathrm{nd}$ year of lactation. Individual measurements emphasized the great differences in this intake among children of the same age. Our study showed that breast milk is an important source of amylase both in developed and developing countries, but there are large variations in intake among children. $(P e$ diatr Res 28: 502-506, 1990)
\end{abstract}

$\alpha$-Amylase (EC 3.2.1.1), present in saliva and pancreatic juice, is the key enzyme in the digestion of starch. Its secretion in saliva is negligible at birth and increases rapidly during the first $3 \mathrm{mo}$ (1). In pancreatic juice, its activity is negligible during the first 6 mo (2-4). Adult levels are reached at the age of $1-2$ y (4-6). The secretion of both salivary and pancreatic amylases is reduced in infants with malnutrition $(5,7,8)$. Breast milk is known to contain an amylase (9-12) that has been shown to survive gastric digestion and remain active in the small intestine (10, 13-15). It has been suggested that, together with pancreatic and salivary amylases and brush-border glucoamylase, breast-milk amylase may take part in the digestion of carbohydrates in breast-fed infants during complementary feeding (16). However, no data are available on quantity and variability of amylase activity in breast milk. In consequence, it is currently not possible to

Received February 22, 1990; accepted June 28, 1990.

Correspondence: Dr. Odile Dewit, Medical Research Council Dunn Nutrition Unit, Downham's Lane, Milton Road, Cambridge CB4 1XJ, England, UK.

Reprint requests: Dr. Ann Prentice, Medical Research Council Dunn Nutrition

Unit, Downham's Lane, Milton Road, Cambridge CB4 1XJ, England, UK. evaluate the potential role of breast-milk amylase in digestion of food carbohydrate given in complement of breast-feeding.

The object of our study was to measure breast-milk amylase activity in two different groups of women practicing prolonged lactation: mothers living in an affluent city of England, and less privileged mothers living in a rural village of The Gambia, West Africa, whose children are at a high risk for malnutrition. The results demonstrated that amylase is secreted into breast milk throughout $2 \mathrm{y}$ of lactation in quantities of potentially valuable digestive capacity and that the activity of this enzyme is remarkably similar in the breast milk of English and Gambian women. The results brought out the great differences in breast-milk amylase activity among mothers living in the same community.

\section{SUBJECTS AND METHODS}

Within-subject variations. Before the main studies, a detailed investigation of within-subject variations in amylase activity was conducted on English and Gambian subjects, to develop a sampling protocol. Within-feed and diurnal variations, and consistency within individuals were examined in five English and five Gambian mothers. The English mothers provided a small sample of milk from both breasts by manual expression, just before and after each feed during a single $24 \mathrm{~h}$ period. The mothers were 27 - to 32-y-old, parity 1-3, and were at various stages of lactation ranging from 4 to $13 \mathrm{wk}$ of lactation. The feed frequency per day was 6-7. The Gambian mothers provided a small sample of milk from both breasts by manual expression at 0800, 1200, 1500, 1800 , and $2100 \mathrm{~h}$ on 3 consecutive days. The mothers were $27-$ to 33 -y-old, parity $6-8$, and were at $5-6$ wk of lactation. In addition, to study within-subject variations during exclusive breast-feeding, a longitudinal study was conducted in a group of seven mothers who were recruited in the lactation clinic of the Helena Venizelos Maternity Hospital, Athens, Greece, where it is clinic policy to recommend exclusive breast-feeding for $6 \mathrm{mo}$. The mothers were 20 - to 37 -y-old, parity $1-4$, and were exclusively breast-feeding throughout the study. The mothers provided small samples of transitional milk (3-11 d postpartum) and sequential samples of mature milk at approximately monthly intervals for 6 mo from both breasts.

Milk collection. On the strength of the results of these studies (detailed later) a simple sampling procedure was adopted for the further studies: amylase was measured in a small sample $(<1$ $\mathrm{mL}$ ) of milk obtained from both breasts on one occasion, irrespective of the suckling pattern, and milk samples from left and right breast were pooled before analysis.

Study communities. Breast-milk amylase was measured in two cross-sectional groups of English and Gambian mothers. The English subjects lived in the Cambridge area and were recruited through local lactation support groups. Fifty-eight mothers par- 
ticipated who were 20 - to 43 years old, parity $1-5$, and at various stages of lactation ranging from 12 to $805 \mathrm{~d}$. All the mothers less than 3 mo postpartum were exclusively breast-feeding, and those greater than 3 mo postpartum had introduced weaning foods into their infants' diets. The mean number of breast-feeds given per day, determined by maternal recall, was $6.6(\mathrm{SD}=2.0)$ for mothers in the 1st trimester of lactation, $5.6(1.0)$ for those in the 2nd trimester, and 4.3 (1.8) for those in the 3rd-9th trimester of lactation. The Gambian subjects lived in the rural, subsistencefarming villages of Keneba, Manduar, and Kanton Kunda. One hundred and two Gambian mothers participated in the study conducted in the dry, postharvest season. The mothers were 16to 49 -y-old, parity $1-12$, and were as $11-748 \mathrm{~d}$ of lactation. The mothers in this community breast-feed on demand (mean frequency of 14 feeds per day) for approximately 2 y and introduce complementary foods around $3 \mathrm{mo}(17)$. They usually have their first baby in late teenage and continue with regular pregnancylactation cycles throughout reproductive life. In consequence, parities of 10 and above are common. This reproduction pattern leads to a very close association between maternal age and parity, and no distinction can be made between the separate effects of these two parameters.

The studies were part of a larger study of breast-milk composition during prolonged lactation and effect of maternal parity, protocols of which were approved by the Ethics Committees of the MRC Dunn Nutrition Unit, Cambridge, UK and the MRC Laboratories, Fajara, The Gambia and by the Board of the Helena Venizelos Maternity Hospital, Athens, Greece.

Determination of amylase activity. All milk samples were stored frozen at $-20^{\circ} \mathrm{C}$ in polystyrene tubes. The method used to determine $\alpha$-amylase activity was derived from Jones et al. (11). Before analysis, samples were quickly thawed and mixed by inversion, and $25 \mu \mathrm{L}$ of milk were diluted $1: 40$ in $50 \mathrm{mM}$ potassium phosphate buffer, $\mathrm{pH} 7.4$, and centrifuged at $1800 \times$ $g$ for $15 \mathrm{~min}$ to remove the cream layer. Activity was measured in $40 \mu \mathrm{L}$ of this diluted, skimmed milk by the hydrolysis of maltotetraose at $37^{\circ} \mathrm{C}$ and the consequent multi-enzyme-linked production of $\mathrm{NADH}$ using $150-\mu \mathrm{L}$ of COBAS reagent for $\alpha-$ amylase (list no. 0710946 Roche Diagnostica, Nutley, NJ), using the COBAS Bio centrifugal analyzer (Roche Diagnostica). One IU of amylase is defined as the activity that hydrolyzes 1 $\mu \mathrm{mol}$ of maltotetraose per min. The measured activity of diluted milk samples was independent of volume used for the assay in the range of $20-50 \mu \mathrm{L}$. The within-day precision of the assay was better than $1 \%$ and day-to-day variation was less than $5 \%$. In a small number of subjects (seven mothers in the 1st trimester of lactation and 14 mothers between 6 and 27 mo of lactation), the total precipitable protein content was measured using a modified bicinchoninic acid method (Pierce) as described earlier (18) to determine the $\mathrm{sp}$ act of amylase (IU/g protein).

Estimation of breast-milk intakes. Breast-milk intake was measured in 10 Gambian infants by the deuterium oxide dilution method using the dose-to-child technique (19), and any food or drink other than breast milk was carefully quantified. For this subset of Gambian infants, breast-milk amylase intake (IU/24 h) was calculated by multiplying breast-milk intake (mL/24 h) by amylase activity (IU/mL). Additional estimates of breast-milk amylase intake of English and Gambian infants were made using breast-milk intake values obtained from detailed studies of the effects of stage of lactation and parity on breast-milk quality and quantity previously carried out in these communities (20). Earlier studies had shown that very high parity has a marked effect on breast-milk output. For the estimations of amylase intake in infants born to mothers of different parity, the following values were used (breast-milk intake expressed in \% of mean): 104 for parity $1 ; 99$ for parity $2-10$; and 85 for very high parity mothers (11 or more) (21).

Data analysis. Measured breast-milk amylase activities showed a positively skewed frequency distribution. Consequently, all values were transformed to logarithms before data processing to normalize the distribution. Values quoted in the text are geometric mean $(x g)$ and values corresponding to antilog of "mean of logged data +1 standard error of logged data," which have been designated as $x g+1 g$ SEM. The mothers were grouped by trimester of lactation, which were defined as follows, from $1 \mathrm{st}$ trimester to 9th trimester, respectively: $12-91 ; 92-182 ; 183-274$; $275-365 ; 366-456 ; 457-547 ; 548-638 ; 639-730$; and $731-821$ $\mathrm{d}$ of lactation inclusive. The parity was defined as the number of live births plus any stillbirths in the last trimester of pregnancy, with twins scored as 2 . Standardization of the data for stage of lactation or parity was achieved by expressing each value as a percentage of the mean value recorded for all the mothers in that community who were in the same period of lactation or of the same parity at the time of sample collection (\% of mean). The adjusted value was a measure of breast-milk amylase activity of the individual relative to the other mothers in the community. The $t$ test for independent or paired values and one-way analysis of variance were used as appropriate to compare groups. The changes in amylase over 6 mo were investigated by regression analysis in the seven mothers practicing exclusive breast-feeding. In this longitudinal study, a quadratic trend in stage of lactation was fitted, with each mother having her own intercept. Thus, the fitted model consisted of seven parallel quadratics in stage of lactation.

\section{RESULTS}

Within-mother short-term variations. Amylase activity showed no significant short-term variations within a subject but each individual exhibited a characteristic level of activity.

There were no consistent variations in amylase activity between the beginning and the end of a feed or among different times of the day in five English mothers (Fig. 1). Amylase activity remained stable over 3 consecutive days in five Gambian mothers (Fig. 2). The variations of amylase activity within each subject for $24 \mathrm{~h}$ or for 3 consecutive days were small, with a combined coefficient of variation of $10.4 \%$ (individual coefficients of variation ranging from 8 to $18 \%$ ). There were no significant differences in amylase activity of milk collected from either breast in four of the five English mothers. One mother (Fig. 1, mother 2) had slightly but consistently higher amylase activity $(p<0.05)$ in samples obtained from her right breast.

The variations within a mother were significantly smaller than

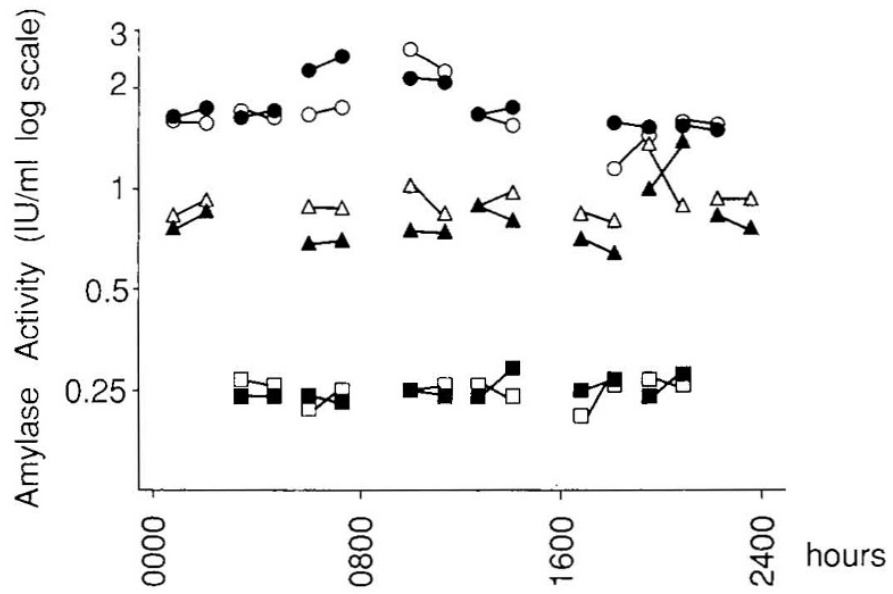

Fig. 1. Within-feed variations of breast-milk amylase activity in three English mothers. Each mother is represented by a different symbol, mother 2 (discussed in text) being represented by triangles. All feeds over a single 24 -h period are represented, and each feed is represented by four marks: the $t$ wo left-hand symbols are for samples taken just before the feed, the two right-hand symbols are for samples taken just after the feed. Samples before and after a feed obtained from the same side are linked by a solid line. The open symbols represent samples from the right breast, and the solid symbols, samples from the left breast. 


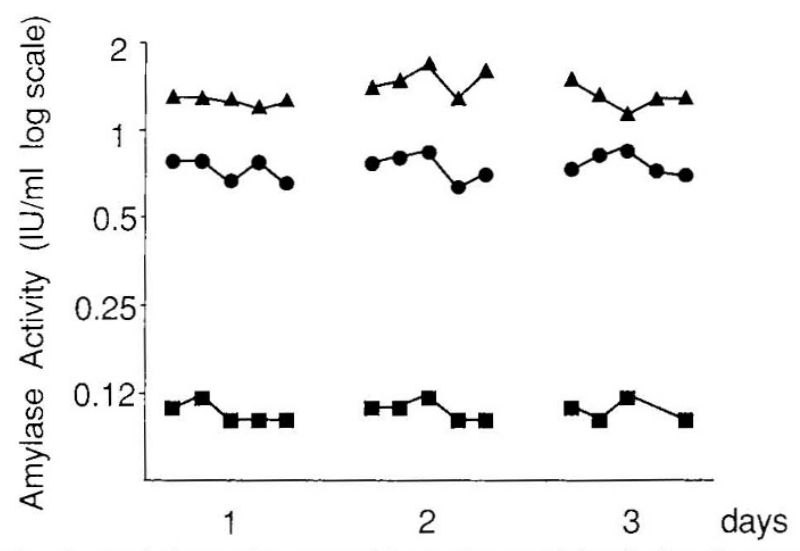

Fig. 2. Variations of breast-milk amylase activity during 3 consecutive days in three Gambian mothers. Each mother is represented by a different symbol. Each mark represents pooled breast milk from left and right breasts. Each mother provided a sample at 0800, 1200, 1500, 1800, and $2100 \mathrm{~h}$ every day for 3 consecutive days. Samples from the same mother during $1 \mathrm{~d}$ are linked by a solid line.

Table 1. Variations in breast-milk amylase activity with stage of lactation in English and Gambian mothers, after adjustment for parity

\begin{tabular}{|c|c|c|c|c|}
\hline \multirow[b]{3}{*}{$\begin{array}{c}\text { Stage of } \\
\text { lactation } \\
\text { (trimester) }\end{array}$} & \multicolumn{4}{|c|}{ Breast-milk amylase activity } \\
\hline & \multicolumn{2}{|c|}{ English } & \multicolumn{2}{|c|}{ Gambian } \\
\hline & $\begin{array}{c}\% \text { of } \\
\text { mean } \\
\text { activity* }\end{array}$ & $n$ & $\begin{array}{c}\% \text { of } \\
\text { mean } \\
\text { activity* }\end{array}$ & $n$ \\
\hline 1 & $145(160) \dagger$ & 19 & $128(144) \dagger$ & 16 \\
\hline 2 & $88(106)$ & 16 & $118(136)$ & 17 \\
\hline $3+4$ & $86(104)$ & 17 & $93(102)$ & 26 \\
\hline$\geq 5$ & $76(112)$ & 6 & $90(97)$ & 43 \\
\hline
\end{tabular}

* Amylase activity expressed as \% of the mean activity in mothers of same parity. Values are geometric mean $x g$ followed by $(x g+1 g$ SEM) as defined in Materials and Methods.

$\dagger t$ test trimester $1 v s$ trimesters $\geq 3: p<0.01$ English, $p<0.02$ Gambian.

the differences in amylase activity among the mothers, inferring that each individual exhibited a characteristic level of amylase activity in her milk (Figs. 1 and 2). This was shown by the analysis of variance that compared the variations of amylase observed within a day in each subject with the differences observed among the five English mothers $(F=397, d f=4,28, p<$ 0.001 ) and the analysis of variance that compared the variations of amylase observed within a period of 3 consecutive days in each subject with the differences among the five Gambian mothers $(F=1124, d f=4,10, p<0.001)$.

Variations with stage of lactation and parity. Amylase activity was measurable in all samples. A 44-fold range of amylase activity was observed, ranging from 0.08 to $3.53 \mathrm{IU} / \mathrm{mL}$. Amylase activity was shown to decrease with the progress of lactation. It was higher in the 1st trimester of lactation (Table 1), and decreased up to 6 mo of lactation. Between 6 and 27 mo of lactation, no further significant changes were observed, and amylase activity was $65 \%$ of that during the 1 st trimester of lactation $(p<0.001)$.

In the group of mothers practicing exclusive breast-feeding, the longitudinal study of amylase activity showed first, that it differed substantially from one mother to another and second, that it decreased by $40 \%$ in the first 5-6 wk of lactation (Fig. 3) to a low plateau thereafter. The curves of log amylase plotted against stage of lactation for the different mothers appeared as parallel quadratic curves in stage of lactation, but with widely differing intercepts $(p<0.0001)$. The quadratic "stage of lacta-

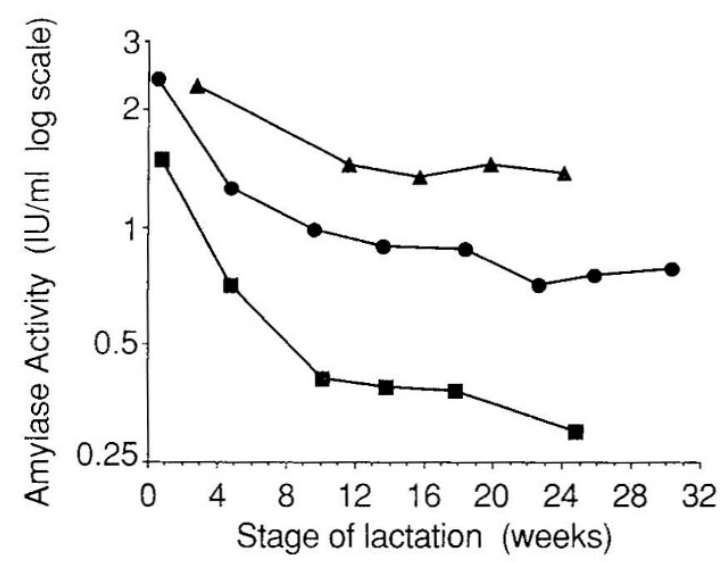

Fig. 3. Variations of breast-milk amylase activity with the stage of lactation in three mothers who were exclusively breast-feeding. Each mother is represented by a symbol and samples from the same mother are linked by a solid line.

tion" term was highly significant $(p<0.0001)$, with $79 \%$ of the variance accounted for by stage of lactation.

In the samples where protein concentration was measured, log amylase activity was positively correlated to protein concentration $(r=0.62 ; n=20 ; p<0.01)$. This was largely an effect of parallel changes of amylase activity and protein concentration with stage of lactation. When mothers were grouped according to the duration of lactation, no correlation between log amylase activity and protein concentration was observed in women of less than 3 mo lactation, but a significant correlation was observed after 6 mo $(r=0.73 ; n=13 ; p<0.01)$. The regression showed that "log amylase activity" (IU/L) was proportional to "protein concentration ${ }^{0.042 "}$ " $(\mathrm{g} / \mathrm{L})$. The change in amylase activity associated with protein concentration therefore was very small in the range of protein content of breast milk. In consequence, expressing amylase as sp act (IU/g protein) did not reduce the large scatter of amylase activity around the mean at each stage of lactation: the coefficients of variation of amylase activity were $51 \%$ in the 1 st trimester and $82 \%$ after 6 mo of lactation.

Very high parity in the Gambian mothers had a marked effect on breast-milk amylase activity. After adjustment for stage of lactation, amylase activity was steady for parity 1-8 but decreased thereafter and, for mothers of parity 11 or 12 , amylase activity was $54 \%$ of that in primiparous mothers $(p<0.001)$. In the English group, where the mothers were of parity 1-5 and aged 20-43 y, parity was related to age to a lesser extent than in the Gambian women. There was no significant effect of either parity or maternal age on amylase activity corrected for stage of lactation.

When both stage of lactation and parity were taken into account, the variation between individuals in each community remained large: the coefficients of variation were $70 \%$ in English mothers and $55 \%$ in Gambian mothers of parity $1-8$.

Amylase activity was of the same order of magnitude in both communities. For example, amylase activity for mothers of parity $1-8$ in the 1 st trimester of lactation was $1.33(1.46)$ and 1.13 (1.30) IU/mL $[x g(x g+1 g$ SEM $)]$ in English $(n=19)$ and Gambian $(n=13)$ mothers, respectively.

Daily supply of amylase to breast-fed infants. Estimations of breast-milk amylase intake by infants using community data indicated that amylase intake is likely to be higher in the 1st trimester, and to decrease to a plateau after the 3rd trimester (Table 2). The combined effect of parity on both breast-milk output and amylase activity resulted in a marked difference in estimated amylase intake and breast-milk intake among the Gambian children in the same age group: infants born to mothers of parity 1-8 had on average an estimated amylase intake of 106 (\% of mean), and those born to mothers of parity 11 or 12 had an intake of 52 . 
Table 2. Calculated estimations of breast-milk amylase intake in Gambian infants

\begin{tabular}{ccccc}
\hline \multicolumn{2}{c}{ Age } & $\begin{array}{c}\text { Amylase } \\
\text { activity } \\
\text { Trimester }\end{array}$ & $\begin{array}{c}\text { Breast-milk } \\
\text { intake } \\
(\mathrm{IU} / \mathrm{mL})\end{array}$ & $\begin{array}{c}\text { Estimated } \\
\text { amylase } \\
\text { intake } \\
(\mathrm{mL} / 24 \mathrm{~h}) \dagger\end{array}$ \\
\hline 1 & $(12-91)$ & 1.11 & 750 & 832 \\
2 & $(92-182)$ & 1.04 & 612 & 636 \\
3 & $(183-274)$ & 0.79 & 608 & 480 \\
4 & $(275-365)$ & 0.67 & 572 & 383 \\
5 & $(366-456)$ & 0.78 & 592 & 462 \\
6 & $(457-547)$ & 0.81 & 514 & 416 \\
\hline
\end{tabular}

* Values are geometric mean.

$\uparrow$ Breast-milk intakes are data from previous studies (reference 20).

The breast-milk amylase intakes varied greatly among infants. Individual breast-milk amylase intakes, measured in a subset of 10 Gambian infants aged 1-3 mo, are presented in Table 3 . This shows that individual values were widely scattered about the community average values, due to variations of both amylase activity among mothers and breast-milk intake among children.

\section{DISCUSSION}

Our study showed that prolonged breast-feeding can supply breast-fed infants and young children with quantities of amylase that may represent a digestive capacity of nutritional interest, but that the quantity varies widely among children. The three major sources of variations of amylase activity in breast-milk were shown to be the mother's characteristic level of amylase in her milk, the duration of lactation, and the maternal parity.

The detailed investigation presented here demonstrated that the short-term variations of breast-milk amylase activity within a woman are very small, and that differences in amylase among mothers are extremely large. This showed that it is therefore possible to obtain a representative assessment of a mother's amylase activity from a single sample of breast milk collected at any time during the day, irrespective of the feeding schedule. In practice, to allow for differences in milk composition between breasts, as was noted here for one English mother and previously in Gambian women during unilateral subclinical mastitis and breast dysfunction $(22,23)$, a small sample was obtained from both breasts each time and aliquots pooled for analysis.

Previous studies have shown that amylase activity is very high in colostrum and decreases during the first weeks of lactation (10-12). In our study, the large number of mothers studied during the 2 nd y of lactation $(n=47)$ and the two mothers studied during their 3rd y demonstrated that amylase activity is present in breast milk throughout prolonged lactation and does not decrease significantly after 6 mo of lactation. It was confirmed in our study that some mothers produce milk with high or low amylase $(10,11)$. During prolonged lactation, the small longitudinal study showed that breast-milk amylase activity remains a characteristic of the mother throughout lactation. The decrease in amylase activity with stage of lactation observed in our study was parallel to that of breast-milk protein concentration reported in a previous cohort (24). Expressing amylase as sp act therefore would be expected to substantially remove the variations due to the duration of lactation. However, the wide variation in amylase activity among individuals at each stage of lactation was shown to be little affected by adjusting for the protein content of the milk.

The breast-milk amylase activity was found to be remarkably similar in the English and Gambian mothers during prolonged lactation despite the marked differences between them, not only in genetic and environmental background, but also in breastfeeding practices. In both English and Gambian women, a very large range of breast-milk amylase activities was observed among mothers, and it was demonstrated that the level of breast-milk amylase observed in each mother was a characteristic of the individual throughout lactation.

Previous studies in The Gambia have shown that lactation performance is altered in high parity mothers $(21,25)$. Mothers of very high parity (parity 10 or more) have lower breast milk and nutrient output than primiparous mothers. In this study, very high parity was found to have a striking effect on breastmilk amylase activity in the Gambian group; women who were of parity 11 or more produced only half as much amylase activity per day as mothers of parity 1-8, regardless of stage of lactation. In the English mothers, parity had no effect on breast-milk amylase activity; this was probably due to the lower parities in this group (parities 1-5).

Breast-milk amylase may have an important role in digestion of carbohydrate of complementary food in the breast-fed infant. In the small intestine, glucose polymers and starch are hydrolyzed by amylase from saliva and pancreatic juice, by brush-border glucoamylase, and, in the breast-fed infant, by breast-milk amylase (10,13-15). Breast-milk amylase, which is of salivary type, is resistant to gastric digestion $(10,13-15)$. In a 10 -mo-old infant, $50 \%$ of total amylase activity in duodenal juice after a human milk feed was accounted for by salivary-type amylase (10) and, in vitro, breast-milk amylase retained a significant proportion of its activity after simulated gastric digestion, especially in the presence of breast-milk proteins, starch, or oligosaccharides (1315). The plausibility of a role for breast-milk amylase in carbohydrate digestion may be evaluated by assessing the likely proportions of amylase activities in the infants' small intestine derived from different sources. Although it is very difficult to estimate the volume of saliva secreted with every meal or per day, the daily output of salivary amylase is on the order of 1000 IU per day in the first months of life (26). In duodenal juice, the output of pancreatic amylase is negligible before $6 \mathrm{mo}$ of age, even after stimulation $(2,3)$. At 6 mo and $1-2$ y of age, the output may be estimated at 300-400 and 4000-6000 IU, respectively, for $50 \mathrm{~min}$ after stimulation, with wide interindividual

Table 3. Measured breast-milk amylase intakes in Gambian infants

\begin{tabular}{|c|c|c|c|c|c|}
\hline Subject & $\begin{array}{c}\text { Maternal } \\
\text { parity }\end{array}$ & Age (d) & $\begin{array}{c}\text { Amylase activity } \\
(\mathrm{IU} / \mathrm{mL})^{*}\end{array}$ & $\begin{array}{c}\text { Breast-milk intake } \\
(\mathrm{mL} / 24 \mathrm{~h}) \dagger\end{array}$ & $\begin{array}{c}\text { Amylase intake } \\
(\mathrm{IU} / 24 \mathrm{~h})\end{array}$ \\
\hline 1 & 1 & 105 & 2.59 & 524 & 1357 \\
\hline 2 & 3 & 92 & 1.54 & 699 & 1076 \\
\hline 3 & 4 & 61 & 0.84 & 651 & 547 \\
\hline 4 & 5 & 65 & 1.00 & 629 & 629 \\
\hline 5 & 6 & 44 & 1.04 & 763 & 793 \\
\hline 6 & 7 & 35 & 1.34 & 832 & 1115 \\
\hline 7 & 7 & 38 & 0.74 & 931 & 689 \\
\hline 8 & 8 & 42 & 0.11 & 829 & 91 \\
\hline 9 & 8 & 37 & 0.41 & 805 & 330 \\
\hline 10 & 9 & 67 & 0.98 & 790 & 774 \\
\hline
\end{tabular}

* Values are geometric mean.

$\dagger$ Breast-milk intakes were measured using the deuterium oxide dilution technique. 
variations (2-4). Breast-milk amylase supply has been calculated using community data and is shown in Table 2 . At the age of 3 mo (trimester 1), breast milk may provide as much amylase as saliva at a time when pancreatic amylase in duodenal juice is negligible. After 9 mo of age (trimesters 4 and above), when pancreatic amylase increases, the contribution of amylase from breast milk decreases but remains substantial up to 18 mo of lactation (trimester 6), and probably into the 3rd year of life.

The measurement of individual intakes of amylase (Table 3) in infants (1st trimester of life) demonstrated that there are considerable differences in the actual breast-milk amylase intake among children in the same age group. The supply of amylase to breast-fed infants will depend on the child's age, multiple factors affecting breast-milk intake, and maternal factors such as level of amylase activity in milk and parity. Gambian infants born to mothers of very high parity (11 or more) receive on average $1 / 2$ the amylase activity of other children of the same age.

The contribution of breast-milk is likely to be increased when the other sources of amylase activity in the small intestine decrease. This may occur in two situations. First, in the case of exocrine pancreatic insufficiency, pancreatic amylase activity is decreased. Exocrine pancreatic insufficiency is generally observed in pathologic situations, but recently it has been shown that even in apparently healthy children in West Africa the exocrine pancreatic function is impaired (27). Second, in the case of malnutrition, both salivary and pancreatic amylase secretions are impaired (7, 8, 27-29), and the damage to the brush border leads to a decrease in glucoamylase activity (30).

Our study demonstrated that prolonged breast-feeding can provide a continuing supply of amylase to infants in both developed and developing countries. This may be of particular importance when the child's needs for digestive enzymes are increased, for example when complementary foods are introduced into the diet, or when the child's endogenous enzymatic production is impaired as a result of pancreatic insufficiency or malnutrition. Our study, however, showed that children are not equal in regard to intake of amylase from breast milk as a result of the very different levels of output of amylase among mothers. Studies in vivo are essential to assess further the extent of breastmilk digestive capacity.

Acknowledgments. The authors thank the mothers in Cambridge, England, and Keneba, The Gambia who participated in our study. We thank Ann Laskey, Themis Zachou, Jacquie Shaw, Sana Ceesay, Linda Taylor, and Lionel Vasquez-Velasquez, who collected and allowed access to the samples, and Tim Cole, who gave advice and support for the statistical analysis. We also thank Roger G. Whitehead for his encouragement. O.D. was a research fellow funded by the Ministry of Research, France.

\section{REFERENCES}

1. Sevenhuysen GP, Holodinsky C, Dawes C 1984 Development of salivary $\alpha-$ amylase in infants from birth to 5 months. Am J Clin Nutr 39:584-588

2. Zoppi G, Andreotti G, Pajno-Ferrara F, Njai DM, Gaburro D 1972 Exocrine pancreas function in premature and full term neonates. Pediatr Res 68:880886

3. Lebenthal E, Lee PC 1980 Development of functional response in human exocrine pancreas. Pediatrics 66:556-560
4. Hadorn B, Zoppi G, Shmerling DH, Prader A, McIntyre I, Anderson CM 1968 Quantitative assessment of exocrine pancreatic function in infants and children. J Pediatr 73:39-50

5. Rossiter MA, Barrowman JA, Dand A, Wharton BA 1974 Amylase content of mixed saliva in children. Acta Paediatr Scand 63:389-392

6. Delachaume-Salem E, Sarles H 1970 Normal human pancreatic secretion in relation to age. Arch Fr Mal Appar Dig 59:136-146

7. Watson RR, Tye JG, McMurray DN, Reyes MA 1977 Pancreatic and salivary amylase activity in undernourished Colombian children. Am J Clin Nutr 30:599-604

8. Barbezat GO, Hansen JDL 1968 The exocrine pancreas and protein-calorie malnutrition. Pediatrics 42:77-92

9. Béchamp A 1883 Sur la zymase du lait de femme. C R Acad Sci 96:15081509

10. Lindberg T, Skude G 1982 Amylase in human milk. Pediatrics 70:235-238

11. Jones JB, Mehta NR, Hamosh M $1982 \alpha$-Amylase in preterm human milk. J Pediatr Gastroenterol Nutr 1:43-48

12. Hegardt P, Lindberg T, Börjesson J, Skude G 1984 Amylase in human milk from mothers of preterm and term infants. J Pediatr Gastroenterol Nutr 3:563-566

13. Heitlinger LA, Lee PC, Dillon WP, Lebenthal E 1983 Mammary amylase a possible alternate pathway of carbohydrate digestion in infancy. Pediatr Res $17: 15-18$

14. Murray RD, Kerzner B, Sloan HR, McClung HJ, Gilbert M, Ailabouni A 1986 The contribution of salivary amylase to glucose polymer hydrolysis in premature infants. Pediatr Res 20:186-191

15. Rosenblum JL, Irwin CL, Alpers DH 1988 Starch and glucose oligosaccharides protect salivary-type amylase activity at acid pH. Am J Physiol 254:G775G780

16. Lebenthal E 1984 Alternate pathways of digestion and absorption in early infancy. J Pediatr Gastroenterol Nutr 3:1-3

17. Prentice AM (ed) 1985 Maternal and child nutrition publications 1974-1984. Dunn Nutrition Unit, Cambridge, UK

18. Prentice A, Ewing G, Roberts SB, Lucas A, MacCarthy A, Jarjou LMA Whitehead RG 1987 The nutritional role of breast-milk IgA and lactoferrin. Acta Paediatr Scand 76:592-598

19. Coward WA, Sawyer MB, Whitehead RG, Prentice AM, Evans J 1979 New method for measuring milk intakes in breast-fed babies. Lancet 2:13-14

20. Prentice AM, Paul A, Prentice A, Black A, Cole T, Whitehead R 1986 Crosscultural differences in lactational performances. In: Hamosh M, Goldman AS (eds) Human Lactation 2: Maternal and Environmental Factors. Plenum, New York, pp 13-14

21. Prentice A 1986 The effect of maternal parity on lactational performance in a rural African community. In: Hamosh $M$, Goldman AS (eds) Human Lactation 2: Maternal and Environmental Factors. Plenum, New York, pp $165-173$

22. Prentice A, Prentice AM 1984 Unilateral breast dysfunction in lactating Gambian women. Ann Trop Paediatr 4:19-23

23. Prentice A. Prentice AM. Lamb WH 1985 Mastitis in rural Gambian mother and the protection of the breast by milk antimicrobial factors. Trans Roy Soc Trop Med Hyg 79:90-95

24. Prentice AM, Roberts SB, Prentice A, Paul AA, Watkinson M, Watkinson AA, Whitehead RG 1983 Dietary supplementation of lactating Gambian women. 1. Effect on breast-milk volume and quality. Hum Nutr Clin Nutr 37C:53-64

25. Prentice A, Jarjou LMA, Drury PJ, Dewit O, Crawford MA 1989 Breast-milk fatty acids of rural Gambian mothers effects of diet and maternal parity. Pediatr Gastroenterol Nutr 8:486-490

26. Bellavia SL, Moreno J, Sanz E, Picas EJ, Blanco A $1979 \alpha$-amylase activity of human neonate and adult saliva. Arch Oral Biol 24:1117-1121

27. Sauniere JF, Sarles H 1988 Exocrine pancreatic function and protein-calorie malnutrition in Dakar and Abidjan (West Africa) silent pancreatic insufficiency. Am J Clin Nutr 48:1233-1238

28. Danus OV, Urbina AM, Valenzuela I, Solimano GC 1970 The effect of refeeding on pancreatic exocrine function in marasmic infants. J Pediatrics 77:334-337

29. Collares EF, Brasil MR 1979 Amilase salivar no kwashiorkor. III. Estudo evolutivo da concentraçao e secreçao em quatro pacientes apresentando complicaçoes durante a recuperaçao nutricional. Arq Gastroenterol 16:3438

30. Lebenthal E, Lee PC 1980 Glucoamylase and disaccharidase activities in normal subjects and in patients with mucosal injury of the small intestine. $J$ Pediatrics 97:389-393 